\title{
ESCREVER SOBRE A HISTÓRIA DAS BIBLIOTECAS HOJE
}

\author{
Raphaële Mouren \\ Doutora em Filologia Grega, The Warburg Institute, \\ University of London, Reino Unido, Centre Gabriel \\ Naudé, École Nationale Supérieure des Sciences \\ de l'Information et des Bibliothèques, Lyon, França. \\ raphaele.mouren@sas.ac.uk \\ https://orcid.org/0000-0001-7637-7267
}

A biblioteca, lugar de conhecimento e cultura, fascina tanto os pesquisadores quanto o grande público. O incêndio da Biblioteca de Alexandria, a grandiosidade da Biblioteca do Congresso são exemplos desse interesse. Atualmente, é possível visitar a primeira, praticamente inteira, no jogo Assassins Creed; já a segunda atrai um grande público que, anualmente, visita suas instalações com exposições permanentes e temporárias, além da biblioteca reconstituída de Thomas Jefferson. No final do século 20 , foi possível acompanhar nos jornais e em outras mídias muitas discussões sobre a construção de novas bibliotecas nacionais, como em Paris ou Londres. No entanto, muito desse interesse também está relacionado ao livro: na memória de uma pequena biblioteca escolar, às vezes, com poucos livros, em uma biblioteca de família, em visitas a uma biblioteca local, em um livro emprestado.

Porém, se esse fascínio é antigo, a disciplina "História das Bibliotecas" é recente. Está parcialmente ligada a uma "História do Livro", que se desenvolveu de forma diferente dependendo do país: nascida da bibliografia material no mundo anglo-saxão, de uma nova corrente de história total na França ( $L$ 'École des Annales), da influência de redes internacionais, seguindo ritmos diferentes em cada local².

\footnotetext{
${ }^{1}$ Tradução: Fabiano Cataldo de Azevedo (UFBA); Marli Gaspar Bibas e Luciana Ferreira Martins (UNIRIO). ${ }^{2}$ Nota da tradução: No Brasil, no contexto da Biblioteconomia, é importante mencionar os seguintes trabalhos: WEITZEL, Simone da Rocha. Origem e fundamentos do processo de desenvolvimento de coleções no Brasil: estudo de caso da Biblioteca Nacional. In: ENCONTRO NACIONAL DE PESQUISA EM CIÊNCIA DA INFORMAÇÃO, 10., 2009, João Pessoa. Anais [...]. João Pessoa: UFPB, 2009. Disponível em: http://repositorios.questoesemrede.uff.br/repositorios/handle/123456789/266?show=full. Acesso em: $18 \mathrm{mar}$ 2021. PEREIRA, Gabriela Lisboa. A história do livro na formação do bibliotecário: análise das disciplinas nas escolas de Biblioteconomia federais. 2018. Trabalho de Conclusão de Curso (Graduação em Biblioteconomia - Escola de Biblioteconomia, Universidade Federal do Estado do Rio de Janeiro, Rio de Janeiro, 2018. Disponível em:

http://www.unirio.br/cchs/eb/arquivos/2018.1/Gabriela\%20Lisboa\%20Pereira.pdf. Acesso em: 16 mar. 2021. FERREIRA, Rubens da Silva. A experiência docente no ensino de História do Livro e das Bibliotecas na Universidade Federal do Pará (UFPA). Informação \& Informação, Londrina, v. 21, n. 1, p. 573-594, jan./abr. 2016. Disponível em: http://www.uel.br/revistas/uel/index.php/informacao/article/viewFile/17384/19009.

Acesso em: 18 mar. 2021

Outro ponto a destacar, como disciplina de História do Livro e das Bibliotecas, ainda que haja uma relação, não é sinônimo de Biblioteconomia de Livros Raros.
} 
A História do Livro, quer inclua a história de um livro ou de um conjunto de livros, leva, naturalmente, à história de coleções e de bibliotecas. A primeira sempre manteve vínculos estreitos com a história de textos e imagens, sendo pesquisada tanto por literários quanto por historiadores da arte. No contexto europeu, a segunda é, essencialmente, uma disciplina de historiadores. No entanto, a história das bibliotecas é transdisciplinar. As pesquisas que podem ser feitas são infinitas: algumas estão mais voltadas para a história de suas construções, outras na organização intelectual e material, ou nos usos da coleção e leitores; mas, geralmente, todos esses aspectos e muitos mais são necessários para completar a história das bibliotecas ou a história de uma biblioteca. História institucional, história das coleções, história dos usos são alguns dos aspectos que o historiador das bibliotecas deve estudar com cuidado. A história aqui se entrelaça com as ciências sociais e políticas, visto que a história das bibliotecas é inseparável da história das sociedades que as criaram.

A história das bibliotecas é, portanto, uma disciplina jovem, na qual há muito o que fazer. As lacunas no nosso conhecimento sobre esse assunto ficaram evidentes quando foram lançadas publicações nacionais como l'Histoire des bibliothèques françaises (1989) ou, mais tarde, a Cambridge History of Libraries in Britain (2006). Delas, novas pesquisas se derivaram.

A história das bibliotecas nacionais costuma ser incompleta ou mesmo desconhecida ${ }^{3}$. Grandes monografias estão se tornando raras, especialmente porque não correspondem mais ao ritmo da pesquisa universitária. Em vez disso, hoje, volumes coletivos e artigos isolados, aos poucos, vão construindo um quadro preciso da história institucional, material e intelectual de uma biblioteca.

Alguns projetos excepcionais contradizem esse cenário como a Storia della Biblioteca Apostolica Vaticana, lançada em 2010, e que, quando estiver concluída será composta por sete grandes volumes que abrangem mais de sete séculos de história (MANFREDI, 2010-). A história das bibliotecas históricas atrai pesquisadores mais do que outras categorias. Na Itália, por exemplo, a Biblioteca Casantense foi estudada, assim como os primeiros séculos de história de bibliotecas como a da Biblioteca Angelica, em Roma, com particular ênfase no papel dos próprios bibliotecários (GREGORIO, 1993; SERRAI, 2005).

3 Um exemplo: BALAYÉ, Simone. La Bibliothèque nationale des origines à 1800. Genebra: Droz, 1988. 
As chamadas bibliotecas públicas são, muitas vezes, esquecidas, mas as situações são muito diferentes de um país para outro. Na França, onde a história dessas bibliotecas está intimamente ligada à história nacional e às consequências da Revolução Francesa, monografias e trabalhos de alunos decifram o campo há cerca de trinta anos, inclusive utilizando métodos comparativos (BARNETT, 2010; BERTRAND, 2010). Por outro lado, guardando as proporções nacionais, as bibliotecas universitárias e científicas ${ }^{4}$ ainda são pouco estudadas.

Sob o viés da História Política, recentemente, algumas pesquisas passaram a direcionar suas abordagens para o contexto do papel das bibliotecas dentro de determinadas sociedades. Esse aspecto não é novo, pois sabemos o lugar que a biblioteca ocupou nos projetos culturais e políticos de príncipes como, por exemplo, o desenvolvimento da biblioteca real e a constituição do depósito legal de Francisco I, bem como a história das duas Bibliotecas Médici, em Florença: a de Cosme, o Velho, no Convento de São Marcos, e a do Grão-duque Cosme I, em São Lourenço.

Estudar o lugar das bibliotecas no projeto político dos governantes, além da interação entre teoria e prática na modernização das bibliotecas, possibilita implementar essa história transdisciplinar e proporcionar melhores resultados (CHAPRON, 2009; BOUCHAREB, 2016). Conhecer essa história recente também deve ser a base para pensar sobre o futuro e a evolução das bibliotecas, o que, muitas vezes, é feito sem essas referências.

Infelizmente, a história dos bibliotecários não foi suficientemente explorada. No entanto, muitas vezes, foram eles que modernizaram e transformaram as bibliotecas e seus usos, ainda que sem ter o tempo necessário para refletir sobre tudo isso. Ao estudar a história das bibliotecas descontextualizada da história dos bibliotecários, corre-se o risco de uma narrativa excessivamente teórica ou técnica que não leva em conta o fator humano que molda o mundo.

Na França, Joseph Van Praet, Léopold Delisle, Julien Cain ainda aguardam que algum trabalho de pesquisa seja dedicado a eles. Anthony Panizzi, diretor da biblioteca

\footnotetext{
${ }^{4}$ Nota da tradução: Nos últimos anos, a história das bibliotecas universitárias, ou pelo menos de algumas de suas coleções, ainda que transversalmente, dependendo da metodologia aplicada, vem sendo desvelada por bibliotecários que pesquisam coleções especiais, por exemplo. Para um cenário de 2010 a 2019, ver: SILVA, Polyanne Ferreira da. Formação e desenvolvimento de coleções especiais: estado da arte, 2010-2019. 2020. 78 f. Trabalho de Conclusão de Curso (Bacharelado em Biblioteconomia) - Escola de Biblioteconomia, Universidade Federal do Estado do Rio de Janeiro, Rio de Janeiro, 2020. Por razões de aderência conceitual, optamos pelo uso de "bibliotecas científicas". Exemplos delas, no Brasil, são as Bibliotecas do Instituto Butantan, Biblioteca do ICICT/Fiocruz, Biblioteca Barbosa Rodrigues (Jardim Botânico do Rio de Janeiro).
} 
do Museu Britânico, em meados do século 19, há pouco mais de cinquenta anos, foi tema de uma biografia, mas é um caso isolado (MILLER, 1967). Um dicionário de bibliotecários publicado em 2020, na França, mostra que o interesse por esses atores está começando a se desenvolver (ANTONUTTI, 2020).

No campo das bibliotecas privadas, há alguns projetos exemplares, como um estudo dedicado a Sir Hans Sloane, dirigido por Alison Walker com o apoio da British Library (WALKER; MACGREGOR, 2012). Porém, apesar de vasto, esse tema é pouco explorado ${ }^{5}$, pois bibliotecas famosas, do passado e do presente, ainda aguardam ser objeto de estudo, mesmo quando seus catálogos ou os próprios livros se encontram disponíveis.

O trabalho que podia ser realizado in loco foi completamente modificado pelo aparecimento dos repositórios de recursos informacionais. Logo, com a disponibilização de milhões de registros bibliográficos em catálogos coletivos e o surgimento de outros dispositivos que permitem o acesso virtual a uma grande parte dos acervos de bibliotecas existentes, a escala de pesquisa mudou muito.

Outra mudança foi no número de exemplares que podemos acessar e, com isso, despertar o interesse nas identificações e descrições das marcas de proveniência; por um longo tempo, essas informações se converteram em metadados muito negligenciados, escondidos ou não pesquisáveis.

O desenvolvimento das humanidades digitais, igualmente, oferece uma nova maneira de estudar bibliotecas, reconstruindo o conteúdo de bibliotecas históricas, quer tenham desaparecido ou que agora estejam integradas em coleções maiores. Esse trabalho pode ser feito de várias formas, que não são exclusivas, dependendo das fontes disponíveis:

- Publicação de antigos inventários e catálogos, manuscritos ou impressos;

- a reconstituição das coleções pela descrição de exemplares localizados ou conhecidos;

- a reconstituição do uso dessas bibliotecas.

\footnotetext{
${ }^{5}$ Nota da tradução: ver: BESSONE, Tania Maria. Introdução. In: BESSONE, Tania Maria. Palácios de Destinos Cruzados: bibliotecas, homens e livros no Rio de Janeiro, 1870-1920. Rio de Janeiro: Arquivo Nacional, 1999, p. 15-26. Neste texto, a autora faz uma revisão de literatura sobre esses estudos do país. Entre alguns bibliotecários, que se dedicam ao campo das bibliotecas privadas, esse livro é considerado como uma obra seminal. Nos últimos vinte anos, ainda que sob uma perspectiva empírica, percebe-se que a Biblioteconomia brasileira vem produzindo sobre esse assunto. Por isso, urge uma pesquisa quantitativa-qualitativa que dê conta desse mapeamento. Como apontado em nota anterior, algumas dessas pesquisas acontecem também no contexto dos trabalhos realizados sobre Coleções Especiais.
} 
A publicação de inventários on-line teve um grande desenvolvimento na França, e recentemente, graças ao projeto Biblissima, financiado pelo Estado, foram disponibilizados os inventários da biblioteca do Cardeal Mazarin, que deram origem ao que hoje é a Biblioteca Mazarine (SORDET, 2016). Outro exemplo é o Bibale, projeto de descrição de manuscritos antigos executado de forma colaborativa entre as bibliotecas a que pertenciam, lançado há cerca de quinze anos na França, foi estendido ao material impresso e também se integrou a uma rede de bibliotecas francesas para a descrição e indicação de proveniência, o que possibilitou a criação de um banco de dados muito rico e de alta qualidade.

Uma das dificuldades que encontramos na história das bibliotecas é que elas raramente são estáticas. São formadas, desmontadas, doadas, dispersas etc. Da magnífica biblioteca reunida em Genebra por Jean-Paul Barbier Muller, logo após os livros terem sido colocados à venda pela Christie's, em março de 2021, apenas os magníficos catálogos que ele editou permaneceram (BARBIER-MUELLER, 1973-2019).

As ferramentas digitais permitem mostrar a evolução da composição de um acervo quando esta informação integral ou parcial está disponível. O projeto Material Evidence in Incunabula, que se concentra em indicações de proveniência, permite que a história de um exemplar seja rastreada ao longo dos séculos através de uma ferramenta de visualização desenvolvida pelo projeto 15thcbook (UNIVERSITY OF OXFORD, s.d.).

A história das bibliotecas nacionais, que passa pela reconstrução da história das coleções que as compõem, e que se integraram ao acervo gradativamente, pode se beneficiar com o progresso das humanidades digitais. Esses estudos, que inicialmente foram realizados de maneira tradicional (por exemplo, a história das origens da British Library), agora, devido à criação de bibliotecas virtuais, é possível ter acesso direto a uma coleção inteira, mesmo que esteja fragmentada dentro de uma biblioteca (MANDELBROTE, 2009).

Alguns projetos vão além, agrupando bibliotecas semelhantes ou contemporâneas, permitindo aos pesquisadores acesso a coleções complementares. Um projeto pioneiro foi a Europeana Regia, que reuniu, virtualmente, bibliotecas que hoje estão dispersas: um conjunto chamado Bibliotheca Carolina (obras-primas dos principais mosteiros e escolas catedrais do Império Carolíngio, séculos 8 e 9); a biblioteca do Rei da França Charles $V$ e de sua família (século 14); e a biblioteca dos reis aragoneses de Nápoles (séculos 15 e 16) (EUROPEANA REGIA, s. d.). 
$\mathrm{Na}$ Grã-Bretanha, os gabinetes de leitura e outras bibliotecas por subscrição, que se desenvolveram significativamente a partir do século 18 , há anos, têm sido objeto de projetos de pesquisa que recorrem aos formatos digitais e computadores para enfatizar as práticas de leitura que as fontes nos permitem, hoje, documentar.

A história da leitura está, de fato, intimamente ligada à das bibliotecas e esses estudos, a maioria dos quais ainda em andamento, mostram os resultados que podem ser extraídos dessas pesquisas ${ }^{6}$. A prática da leitura é o aspecto mais difícil de entender na história das bibliotecas: cada um de nós sabe, por experiência própria, que podemos ter um livro e nunca lê-lo.

\section{Um ator importante para o desenvolvimento da história das bibliotecas são os} próprios bibliotecários. Na gestão das coleções, eles as conhecem melhor do que ninguém, têm acesso aos livros e às fontes.

Dentre os nomes citados neste artigo, muitos são bibliotecários. Contudo, entrar neste campo de estudo exige um esforço para quem não estudou História: o de familiarizar-se com os métodos da pesquisa histórica e sociológica. Isso é imprescindível, sob o risco de se fazer apenas um trabalho descritivo, incompleto, enviesado. Esse processo é mais fácil de ser realizado quando o ensino de biblioteconomia incorpora a História do Livro e das Bibliotecas, para que, já na graduação, os futuros bibliotecários possam se familiarizar com esse conteúdo e método ${ }^{7}$.

Os projetos de pesquisa sobre a reconstituição de bibliotecas, públicas ou privadas, a partir das fontes disponíveis, implicam não só uma reflexão sobre o método de trabalho histórico, mas também sobre o público a que se destinam tais estudos e sobre os seus objetivos.

Essas reflexões podem ser verticalizadas graças aos avanços das humanidades digitais, pois o pesquisador sem contratempos pode planejar pesquisas mais complexas e detalhadas. Ele, igualmente, consegue preparar a estruturação desses dados

\footnotetext{
${ }^{6}$ Ver, por exemplo, dois projetos em andamento: Libraries, Reading Communities and Cultural Formation in the Eighteenth-Century Atlantic, dirigido por Mark Towsey:

https://gtr.ukri.org/projects?ref=AH\%2FS007083\%2F1 e também Books and Borrowing 1750-1830, dirigido por Katie Halsey: https://borrowing.stir.ac.uk/

${ }^{7}$ Nota de tradução: fazendo uma aproximação ao nosso contexto, além da clara necessidade de inclusão de conteúdos sobre história do livro e das bibliotecas (uma vez que podem ser considerados parte do conjunto propedêutico da formação de um bibliotecário), o que se orienta é também a possibilidade de o aluno ter acesso às metodologias de pesquisa voltadas para a escrita da história. Tudo isso poderia não apenas estimular mais pesquisas, mas tornar mais fácil os trabalhos dos bibliotecários que desejam se dedicar ao tema.
} 
com antecedência e, para isso, deve imaginar os usos possíveis do seu trabalho, muito além do que ele espera de sua própria pesquisa.

Nesse sentido, esse investigador deve considerar que ele vai formatar e colocar à disposição os dados coletados, os quais poderão ser utilizados no desenvolvimento de novas pesquisas por alunos e também por dois grupos de bibliotecários, isto é, aqueles que estudam e desenvolvem pesquisas sobre o próprio acervo e aqueles que pesquisam outras bibliotecas.

A interoperabilidade aqui é crucial, pois a reunião de estudos sobre bibliotecas e bibliotecários auxilia numa compreensão mais ampla de suas histórias. Por isso, atualmente, os projetos coletivos podem ser a solução para suprir a escassez e/ou a dificuldade de estudos sobre as bibliotecas mais importantes.

Um bom exemplo de pesquisa coletiva ${ }^{8}$ é o projeto sobre a história da Bibliothèque d'art et d'archéologie de Jacques Doucet, origem da biblioteca de história da arte da Université de Paris, e, mais recentemente, conhecida como biblioteca do Institut National d'Histoire de l'Art, agora instalada nas salas históricas da Biblioteca Nacional.

Para que a História das Bibliotecas se desenvolva, ela precisa estar apoiada também em estudos de caso que abrirão caminho para pesquisas mais amplas. A estratégia adotada por esse Dossiê permite reunir trabalhos com diferentes abordagens e ajuda o leitor a compreender a complexidade deste campo. Esta é, sem dúvida, a melhor forma de enriquecer o conhecimento e a compreensão das nossas bibliotecas.

Santo Albano, março de 2021.

\section{REFERÊNCIAS}

ANTONUTTI, Isabelle (ed.). Figures de bibliothécaires. Villeurbanne: Presses de l'Enssib, 2020. MANFREDI, Antonio; CERESA, Massimo; MONTUSCHI, Claudio; JATTA, Barbara; RITA, Andreina. Storia della Biblioteca apostolica vaticana. Cidade do Vaticano: Biblioteca apostolica vaticana, 2010- .

BARBIER-MUELLER, Jean-Paul. Ma bibliothèque poétique. Genebra: Droz, 1973-2019. 11v. BARNETT, Graham Keith. Histoire des bibliothèques publiques en France de la Révolution à 1939. Paris: Promodis, 1987.

BERTRAND, Anne-Marie Bertrand. Bibliothèque publique et public library: essai d'une généalogie comparée. Villeurbanne: Presses de l'Enssib, 2010.

\footnotetext{
8 https://www.inha.fr/fr/recherche/le-departement-des-etudes-et-de-la-recherche/domaines-derecherche/histoire-et-theorie-de-I-histoire-de-I-art-et-du-patrimoine/la-bibliotheque-d-art-et-d-archeologie-dejacques-doucet.html
} 
BOUCHAREB, Hind. Penser et mettre en œuvre la lecture publique: discours, débats et initiatives (1918-1945). Orientadores: Anne-Marie Bertrand e Dominique Varry. 2016. Tese (Doutorado em História) - Universidade de Lyon, Lyon, 2016.

CHAPRON, Emmanuelle. Ad utilita pubblica: politique des bibliothèques et pratiques du livre à Florence au XVIII' siecle. Genebra: Droz, 2009.

EUROPEANA REGIA. Disponível em: http://www.europeanaregia.eu. Acesso em: 18 mar. 2021. GREGORIO, Vincenzo De. La Biblioteca Casanatense di Roma. Nápoles: Edizioni scientifiche italiane, 1993.

MANDELBROTE, Giles; TAYLOR, Barry (ed.). Libraries within the library: the origins of the British Library printed collections. Londres: British Library, 2009.

MILLER, Edward. Prince of librarians: the life and times of Antonio Panizzi of the British Museum. Athens: Ohio University Press, 1967.

SERRAI, Alfredo. Angelo Rocca fondatore della prima biblioteca pubblica europea. Milão: Edizioni Sylvestre Bonnard, 2005.

WALKER, Alison; MACGREGOR, Arthur (ed.). From books to bezoars: Sir Hans Sloane and his collections. Londres: the British Library, 2012. BRITISH LIBRARY (Reino Unido). Sloane printed books. Disponível em: http://www.bl.uk/catalogues/sloane/. Acesso em: 18 mar. 2021.

SORDET, Yann. Reconstructing Mazarin's library: libraries in time and space, sources, tools and hypothesis. Quaerendo, Leiden, v.46, n.2/3, 2016, p.151-164. 